\title{
$\mathrm{M}|\mathrm{R}| \mathrm{S}$ Internet Journal Nitride Semiconductor Research
}

\section{Characteristic of InGaN/GaN Laser Diode Grown by a Multi-Wafer MOCVD System}

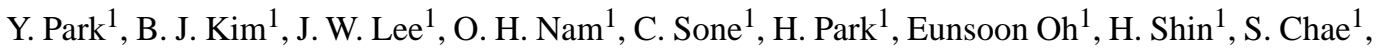 \\ J. Cho ${ }^{1}$, Ig-Hyeon Kim ${ }^{1}$, J.S. Khim ${ }^{1}$, S. Cho ${ }^{1}$ and T.I. Kim ${ }^{1}$ \\ ${ }^{1}$ Samsung Advanced Institute of Technology,
}

(Received Wednesday, January 6, 1999; accepted Tuesday, January 19, 1999)

InGaN/GaN multi-quantum well (MQW) laser diodes (LDs) were grown on c-plane sapphire substrates using a multi-wafer MOCVD system. The threshold current for pulsed lasing was 1.6 A for a gain-guided laser diode with a stripe of $10 \times 800 \mu \mathrm{m}^{2}$. The threshold current density was 20.3 $\mathrm{kA} \mathrm{cm}^{-2}$ and the threshold voltage was $16.5 \mathrm{~V}$. The optical power ratio of transverse electric mode to transverse magnetic mode was found to be greater than 50 . The characteristic temperature measured from the plot of threshold current versus measurement temperature was between 130 and $150 \mathrm{~K}$.

\section{Introduction}

Nitride semiconductor short wavelength laser diodes (LD) have attracted much attention as a light source for the optical data storage. Since Nichia Co. reported pulsed lasing in an InGaN multi-quantum well (MQW) LD in the end of 1995, [1] significant progress has been made in the development of blue LD's. Nakamura et al. has already demonstrated a blue LD with lifetime in excess of 10,000 hrs. [2] Although Nichia's conspicuous successes have stimulated the nitride research society during the last three years, until recently a limited number of research groups in the United States and Japan reported continuous wave [3] [4] [5] or pulsed lasing. [6] [7] [8] [9] In this paper, we report InGaN/ GaN MQW LD operated under pulsed conditions.

\section{Experiment}

The LD structure shown in Figure 1 was grown on a cplane sapphire substrate using a multi-wafer MOCVD system into which three 2" wafers can be loaded in a time. To our knowledge, this is the first report on InGaN/GaN MQW LD grown by a mass production scale MOCVD reactor in the open literature. TMGa, TMIn, TMAl, $\mathrm{Cp}_{2} \mathrm{Mg}, \mathrm{NH}_{3}$, and $\mathrm{SiH}_{4}$ were used as material sources for the structure growth. The reactor pressure was maintained at 100 torr during the growth. In order to form gain guided LD's the structure was etched using chemically assisted ion beam etching (CAIBE) until the n-type GaN layer was exposed. A Pd/
$\mathrm{Au}$ contact was formed onto the p-type $\mathrm{GaN}$, and a Ti/Al contact onto the $\mathrm{n}-\mathrm{GaN}$. The laser facets were formed by CAIBE. No mirror coating was employed on the facet surface. Fabricated LDs were measured under pulsed current conditions with pulse widths ranging from $100 \mathrm{~ns}$ to $1 \mu \mathrm{sec}$ at $1 \mathrm{kHz}$.

\section{Results}

Figure 2, Figure 3, Figure 4, Figure 5 show typical features proving that the diodes lased. Figure 2 shows L-I$\mathrm{V}$ characteristics of one of the LDs with a stripe of 10 $\mu \mathrm{m} \times 800 \mu \mathrm{m}$. The lowest threshold current was found to be $1.6 \mathrm{~A}$, corresponding to a threshold current density of $20.3 \mathrm{kA} \mathrm{cm}^{-2}$. The threshold voltage of the device at the threshold current was $16.5 \mathrm{~V}$. Figure 3 shows the polarized light output intensity as a function of current for another $\mathrm{LD}$, whic hwas measured under a pulse condition of $200 \mathrm{~ns}$ width at $1 \mathrm{kHz}$. It is clear that the emission was strongly polarized in transverse electric (TE) mode above the threshold current of $1.9 \mathrm{~A}$, which is a good indication of lasing operation. The ratio of TE to transverse magnetic (TM) mode was found to be larger than 50. Figure 4 shows optical spectra of one of the LD's. The spectra were collected using a monochromator and a photon multiplier with a resolution of $0.1 \mathrm{~A}$. Above the threshold current, strong and well-defined mode spectra were observed. They have several groups of sub-band emissions in the wavelength range of 415 to $421 \mathrm{~nm}$ with a peak spacing of around $0.72 \mathrm{~nm}$. Figure 
5 illustrates a narrow far-field pattern of the stimulated emission.

The sub-band emissions in the spectra shown in Figure 4 are known to be composed of many longitudinal modes. [5] [10] Figure 6 is a spectrum obtained at a higher resolution on the LD wit ha stripe of $10 \mu \mathrm{m} \times 800$ $\mu \mathrm{m}$. The sample was measured with a pulse width of 1 $\mu \mathrm{sec}$ at $1 \mathrm{kHz}$. It is observed that each sub-band consists of several sharp peaks with a separation of $0.043 \mathrm{~nm}$. Assuming that these peaks arises from the longitudinal modes of the LD, the mode separation $\Delta \lambda$ is given by

$$
\Delta \lambda=\lambda_{0}^{2} / 2 \operatorname{Ln}
$$

where $\mathrm{n}$ is the effective refractive index, $\lambda_{0}$ is the emission wavelength, and $\mathrm{L}$ is the cavity length. Given the values, $0.043 \mathrm{~nm}, 416.6 \mathrm{~nm}$, and $800 \mu \mathrm{m}$ for $\Delta \lambda, \lambda_{\mathrm{o}}$, and $\mathrm{L}$, respectively, we obtained 2.52 as the refractive index $\mathrm{n}$. This value is close to a value calculated from the optical modes of the structure and similar to a value Nakamura et al. used in their early work on the pulsed lasing. [11] However, somewhat larger effective refractive indexes of 3.3 and 3.6 have been reported in other papers. [5] [10]

Figure 7a shows L-I characteristics of one of the LD's with a stripe of $10 \mu \mathrm{m} \times 1200 \mu \mathrm{m}$ at different temperatures ranging from 0 to $100{ }^{\circ} \mathrm{C}$. The pulse width was $200 \mathrm{~ns}$ at $1 \mathrm{kHz}$. As shown in Figure 7a, the LD lased up to a temperature as high as $100^{\circ} \mathrm{C}$. However, the $\mathrm{LD}$ showed a degradation phenomenon at $100^{\circ} \mathrm{C}$. It failed at greater current than $5 \mathrm{~A}$. It is certain that with increasing measurement temperature threshold current increases. The temperature dependence of threshold current is shown in Figure 7b. The calculated characteristic temperature was $155 \mathrm{~K}$ for around room temperature operation and $133 \mathrm{~K}$ for higher temperature operation. These values are comparable to those of other group's InGaN LDs. [5] [10] [12] Kuramata et al. has reported a similar change in the characteristic temperature. [5] It is worth noting that the LD showed a kink in the L-I plot at temperatures higher than $60^{\circ} \mathrm{C}$ with more apparent appearance at higher temperature. Nakamura et al. suggested that such a kink in the L-I plot for their high power LD was due to the change in emission mode. [13] More work is necessary to verify the origin of the kink.

\section{Conclusion}

We demonstrated the room temperature pulsed lasing of InGaN/GaN MQW blue LD grown by a multi-wafer
MOCVD system. Threshold current density was found to be $20.3 \mathrm{kA} \mathrm{cm}^{-2}$ for $10 \mu \mathrm{m} \times 800 \mu \mathrm{m}$ stripe LD. The operating voltage at this threshold current density was $16.5 \mathrm{~V}$. Above the threshold current a strong and welldefined emission mode with a peak spacing of $0.72 \mathrm{~nm}$ was observed. The refractive index calculated from the spacing between longitudinal modes was 2.52. The measured characteristic temperature was between 130 and $150 \mathrm{~K}$.

\section{REFERENCES}

[1] S Nakamura, M Senoh, S Nagahama, N Iwasa, T Yamada, T Matsushita, H Kiyoku, Y Sugimoto, Jpn. J. Appl. Phys. 35, L74-L76 (1996).

[2] "InGaN/GaN/AlGaN-Based Violet Laser Diodes with a Lifetime of More than 10,000 Hours", S. Nakamura, M. Senoh, S. Nagahama, N. Iwasa, T. Matsushita, and T. Mukai, Proceedings of $2^{\text {nd }}$ ISLLED, 371 (September 29 - October 2, 1998, Chiba, Japan)

[3] G.E. Bulman, K. Doverspike, S.T. Sheppard, T.W. Weeks, H.S. Kong, H.M. Dieringer, J.A. Edmond, J.D. Brown, J.T. Swindell, J.F. Schetzina, Electron. Lett. 33, 1556-1557 (1997).

[4] T. Kobayashi, F. Nakamura, K. Nagahama, T. Tojyo, H. Nakajima, T. Asatsuma, H. Kawai, M. Ikeda, Electron. Lett. 34, 1494 (1998).

[5] A. Kuramata, S. I. Kubota, R. Soejima, K. Domen, K. Horino, T. Tanahashi, Jpn. J. Appl. Phys. 37, L1373 (1998).

[6] I. Akasaki, S. Sota, H. Sakai, T. Tanaka, M. Koike, H. Amano, Electron. Lett. 32 , 1105-1106 (1996).

[7] K. Itaya, M. Onomura, J. Nishio, L. Sugiura, S. Saito, M. Suzuki, J. Rennie, S. Nunoue, M. Yamamato, H. Fujimoto, Y. Kokobun, Y. Ohba, G. Hatakoshi, M. Ishikawa, Jpn. J. Appl. Phys. 35, 11315-11317 (1996).

[8] M.P. Mack, A. Abare, M. Aizcorbe, Peter Kozodoy, S. Keller, U. K. Mishra, L. Coldren, Steven DenBaars, MRS Internet J. Nitride Semicond. Res. 2, 41 (1997).

[9] Y. Kimura, M. Miyachi, K. Takahashi, T. Tanaka, M. Nishitsuka, A. Watanabe, H. Ota, K Chikuma, Jpn. J. Appl. Phys. 37, L1231 (1998).

[10] S Nakamura, M Senoh, S Nagahama, N Iwasa, T Yamada, T Matsushita, Y Sugimoto, H Kiyoku, Appl. Phys. Lett. 70, 1417-1419 (1997).

[11] Shuji Nakamura, Gerhard Fasol, The Blue Laser Diode - GaN based Light Emitters and Lasers , (Springer-Verlag, Heidelberg, 1997), .

[12] S. Nakamura, M. Senoh, S. Nagahama, N. Iwasa, T. Yamada, T. Matsushita, Y. Sugimoto, H. Kiyoku, Appl. Phys. Lett. 69 , 3034-3036 (1996).

[13] S. Nakamura, M. Senoh, S. Nagahama, N. Iwasa, T. Yamada, T. Matsushita, H. Kiyoku, Y. Sugimoto, T. Kozaki, H. Umemoto, M. Sano, K. Chocho, Jpn. J. Appl. Phys. 37, L627 (1998). 


\section{FIGURES}

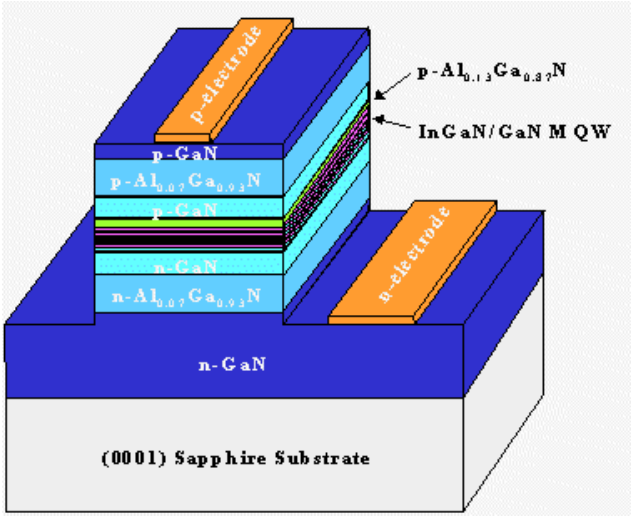

Figure 1. A schematic of the fabricated LD

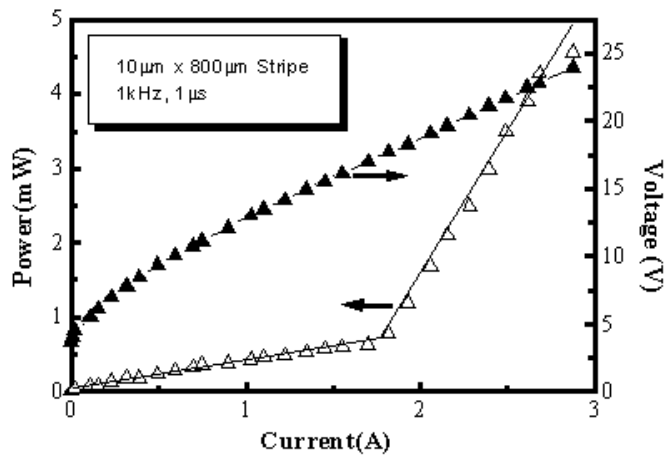

Figure 2. L-I-V characteristic of the LD

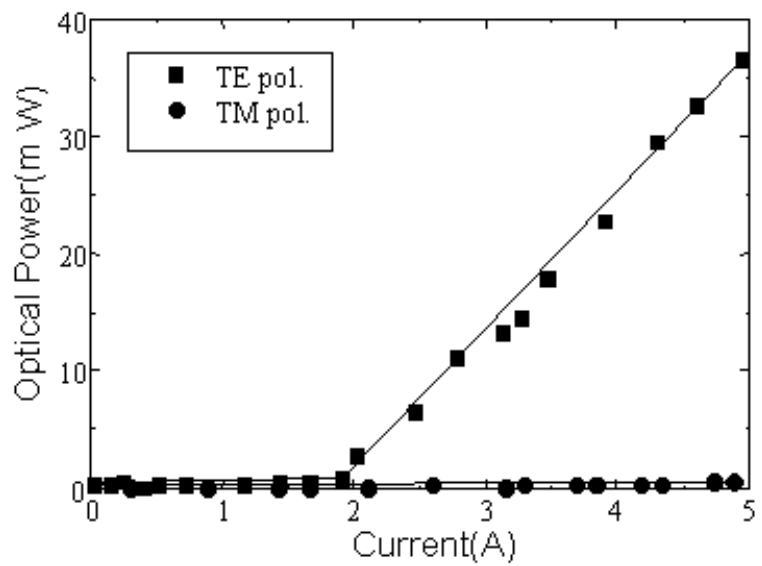

Figure 3. Polarized light output intensity of the LD.

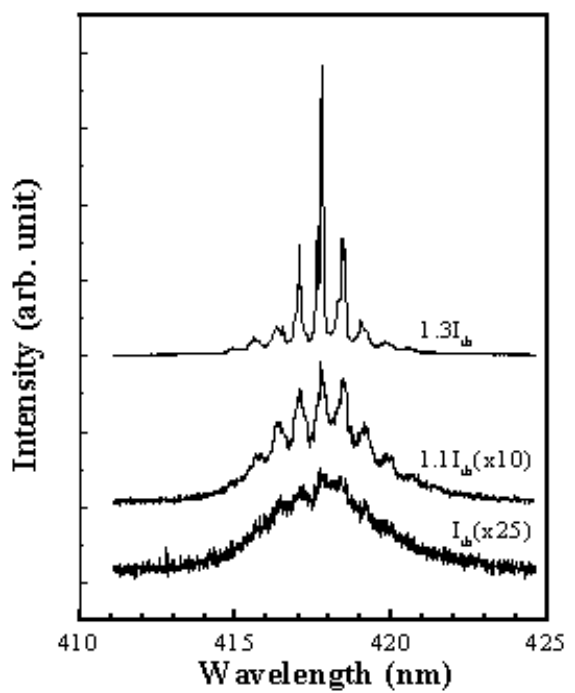

Figure 4. Spectra of the pulsed lasing

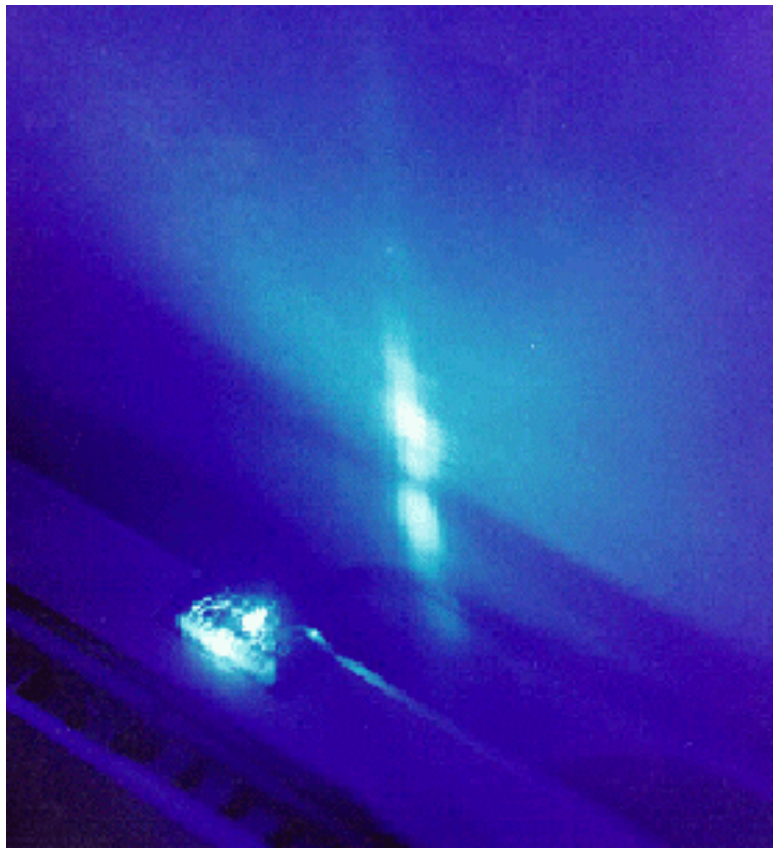

Figure 5. A far-field pattern of pulsed lasing. 


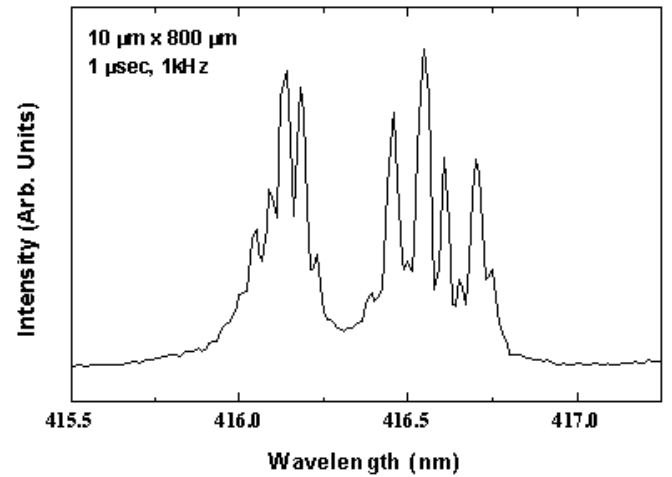

Figure 6. Subband emission consisting of sharp longitudinal modes.

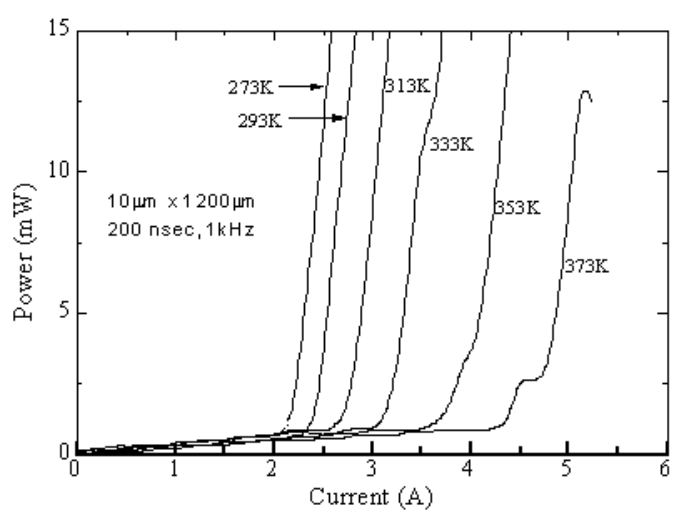

Figure 7a. Temperature dependence of L-I characteristics of the LD

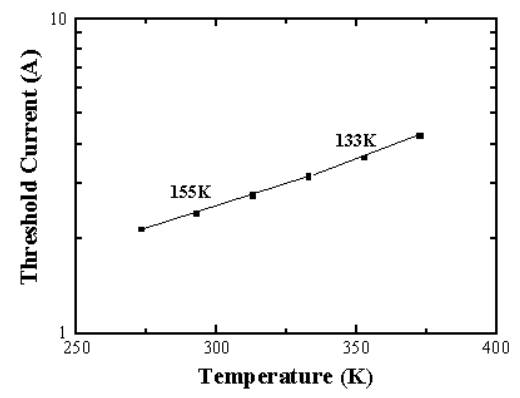

Figure $7 \mathrm{~b}$. Threshold current as a function of measurement temperature. 